\title{
PENGENDALIAN PERSEDIAAN INSERT TOOLS DENGAN METODE ECONOMIC ORDER QUANTITY DAN KLASIFIKASI ABC
}

\author{
Amanda Sofiana*, Diki Ahmad Tasdiqul Haq \\ Jurusan Teknik Industri, Fakultas Teknik, Universitas Jenderal Soedirman \\ Email: amanda.sofiana@unsoed.ac.id; dikiathq@gmail.com
}

Artikel masuk : 14-04-2020

Artikel direvisi : 27-05-2020

Artikel diterima : 16-06-2020

${ }^{*}$ Penulis Korespondensi

\begin{abstract}
Abstrak -- PT. XYZ merupakan perusahaan yang bergerak di bidang otomotif yang memproduksi komponen kendaraan dan perakitan mesin. Pengendalian persediaan yang mendukung proses produksi merupakan suatu proses internal yang cukup vital bagi operasional perusahaan otomotif karena banyaknya mesin serta target produksi untuk memenuhi permintaan konsumen. Insert tools merupakan salah satu alat yang sangat penting dalam memastikan keberlangsungan proses produksi yang menggunakan mesin CNC. Potensi terjadinya kerusakan dan masa pakai yang habis dapat terjadi kapan saja, hal ini berarti persediaan insert tools harus selalu tersedia untuk digunakan pada waktunya. Penelitian ini menyediakan solusi bagi masalah pengendalian persediaan perusahaan. Dengan menggunakan metode EOQ perusahaan dapat menentukan pembelian yang optimal sehingga dapat meminimumkan total biaya inventory. Selain itu, Klasifikasi $A B C$ digunakan untuk menentukan prioritas insert tools yang memerlukan perhatian lebih dalam pengendalian persediaannya. Hasil penelitian ini adalah keputusan persediaan jumlah order quantity yang optimal dan ekonomis dari berbagai insert tools, jumlah safety stock dan reorder point. Hasil klasifikasi ABC, dari 27 insert tools diklasifikasikan menjadi: 6 jenis insert tools kelas A, 5 jenis kelas $B$ dan 16 jenis kelas $C$. Hasil klasifikasi ini bisa digunakan perusahaan untuk prioritas pengamanan persediaan insert tools.
\end{abstract}

Kata kunci: EOQ; Insert Tools; Klasifikasi ABC; Pengendalian Persediaan

\begin{abstract}
PT. $X Y Z$ is a company engaged in the automotive sector, which produces vehicle components and engine assembly. Inventory control that supports the production process is an internal process that is vital for automotive company operations because of the large number of machines and production targets to meet consumer demand. Insert tools are one of many factors that are very important in ensuring the sustainability of the production process that uses CNC machines. Potential damage and end of tools life can occur at any time, and this means that insert tools inventory must always be available for use on time. This research provides a solution to the company's inventory control problem. By using the EOQ method, the company can determine the optimal purchase to minimize total inventory costs. Besides, $A B C$ Classification is used to determine the priority of insert tools that require more attention in controlling the inventory. The results of this study are inventory decisions such as the order quantity, the amount of safety stock, and reorder points of the insert tools. The results of $A B C$ classification, from 27 insert tools, are classified into: 6 types of class $A$ insert tools, five types of class $B$, and 16 types of class $C$. The results of this classification can be used by companies to prioritize securing inventory insert tools.
\end{abstract}

Keywords: EOQ; Insert Tools; ABC Classification; Inventory Control 


\section{PENDAHULUAN}

Pengendalian persediaan raw material, spare part dan cutting tools yang mendukung proses produksi, merupakan suatu proses internal yang cukup vital dan penting bagi operasional perusahaan otomotif (Graystone, 1997). Cutting tools merupakan salah satu di antara banyak faktor yang sangat penting dalam memastikan keberlangsungan proses produksi. Potensi terjadinya kerusakan dan masa pakai yang habis dapat terjadi kapan saja. Hal ini membuat persediaan tools ini harus selalu tersedia untuk digunakan kapan saja. Salah satu bagian cutting tools, yaitu insert adalah ujung cutting yang removable, atau tidak dipatri atau dilas pada body tool. Insert biasanya indexable, artinya bisa di putar tanpa mempengaruhi geometri tool.

PT. XYZ merupakan suatu industri manufaktur yang bergerak di bidang otomotif yang memproduksi komponen kendaraan dan perakitan mesin. Saat ini pengadaan tools di PT. XYZ masih mengikuti jumlah permintaan produk yang diterima. Pengadaan jumlah tools didasarkan pada tools life tersebut. Pengadaan dilakukan saat pada dibutuhkan saja artinya bagian gudang tools tidak melakukan pengadaan ketika tidak ada permintaan produksi. Apabila stok mulai habis dan permintaan produksi tinggi maka pengadaan tools harus dilakukan dengan memilih vendor yang tepat dan cepat supaya kebutuhan dapat terpenuhi. Hal tersebut akan menyebabkan shortage karena adanya lead time pengiriman dan biaya berlebih. Permintaan dan lead time yang bervariasi memerlukan pengelolaan secara tepat. Penentuan kuantitas pemesanan dan reorder point yang tepat sangat berpengaruh terhadap besarnya biaya persediaan (Lukitosari, 2012).

EOQ (Economic Order Quantity) adalah metode yang berkaitan dengan jumlah pesanan yang dapat meminimumkan total biaya persediaan dan pembelian yang optimal. EOQ dapat digunakan untuk mencari berapa total kuantitas material yang tetap untuk dibeli dalam setiap kali pembelian untuk menutupi kebutuhan per periode (Yamit, 2005). Implementasi EOQ mampu menyelesaikan permasalahan persediaan suku cadang (Indriastuty, et,al., 2018) dan spare parts perakitan motor (Octaviana, Baihaqi, \& Bramanti, 2018). Penelitian Sato \& Jauhari (2019) juga menggunakan metode EOQ dalam menentukan kebijakan persediaan suku cadang kritis dalam perusahaan pengeboran minyak. Metode EOQ juga dipakai sebagai pengendalian persediaan multi item dengan diskon kuantitas dalam penelitian (Nilawati \& Giyanti, 2016).

Semakin banyak variasi untuk satu jenis produk, menyebabkan semakin banyak alokasi investasi untuk menjaga jangan sampai satu produk mengalami stock out (Purnomo, 2018). Banyaknya tipe tools yang berbeda membuat perusahaan membutuhkan informasi prioritas tools dalam kebijakan persedian. Informasi ini digunakan untuk memberikan perhatian lebih pada tipe yang mempunyai nilai penggunaan yang relatif tinggi/mahal. Analisis atau Klasifikasi ABC merupakan klasifikasi suatu kelompok material, bahan baku atau aset dalam susunan yang menurun berdasarkan nilai biaya penggunaan material itu per periode waktu (harga per unit material atau aset dikali volume penggunaan material tersebut dalam periode waktu tertentu (Gaspersz, 2005). Klasifikasi membutuhkan cara dalam menentukan tingkat layanan persediaan yang dapat mendukung produksi dan layanan (Wibawa \& Pujawan, 2013). Beberapa penelitian tentang klasifikasi $A B C$ mampu membantu perusahaan menyelesaikan masalah penggolongan jenis persediaan yang sesuai dengan kelasnya (Budiningsih \& Jauhari, 2017; Farida \& Rozini, 2016; Risyahadi \& Putri Yunan, 2019).

Berdasarkan latar belakang tersebut, penelitian bertujuan untuk mengendalikan persediaan insert tools di PT. XYZ. Penelitian ini menggunakan metode EOQ untuk proses pengendalian persediaan yang dapat meminimalkan biaya dan klasifikasi $A B C$ sebagai pengelompokkan pengendalian persediaan untuk mengetahui komponen yang memiliki investasi yang tinggi dan yang bernilai rendah. Dengan mengetahui nilai investasi maka perusahaan dapat menjaga persediaan dari komponen tersebut.

\section{METODE PENELITIAN}

Penelitian ini diawali dengan melakukan studi lapangan untuk melihat secara langsung prosedur penggunaan tools di PT. XYZ. Pada studi lapangan, observasi dilakukan untuk mengetahui metode pengendalian persediaan yang digunakan oleh perusahaan, wawancara untuk mengumpulkan informasi yang diperlukan, serta dokumentasi untuk mendapatkan data pada penelitian.

Dari hasil studi lapangan, diketahui banyaknya tools di PT. XYZ seringkali menimbulkan masalah bagi user pabrik dimana pembelian insert tools tidak efisien dan memakan biaya cukup besar. Pengumpulan data dilakukan melalui wawancara dengan bagian maintenance PT. XYZ untuk mengetahui prosedur pengolahan data tools di perusahaan, wawancara dengan manager purchasing dan manager maintenance untuk mengetahui biaya penyimpanan tools serta dengan staff maintenance untuk mengetahui biaya setiap penggunaan insert tools. Selain itu, pengambilan data dilakukan dengan dokumentasi untuk mendapat data harga, permintaan, dan jumlah permintaan insert tools tahun 2019-2020. 


\section{Economic Order Quantity (EOQ)}

Pada tahap pengolahan data, metode $\mathrm{EOQ}$ digunakan untuk mencari kebijakan persediaan terbaik pada insert tools. Dalam penelitian ini dilakukan perhitungan jumlah kuantitas pesanan optimal untuk 1 tahun, safety stock dan reorder point (ROP). Konsep utama EOQ yaitu membuat keseimbangan antara biaya pesan (ordering cost) dan biaya penyimpanan (holding cost). Keseimbangan antara biaya pesan (ordering cost) dan biaya penyimpanan (holding cost).

$Q=\sqrt{\frac{2 D S}{H}}$

Keterangan:

$Q$ : Jumlah optimum unit per pesanan (EOQ)

$D$. Permintaan tahunan dalam unit barang

: persediaan

$S$ : Biaya pemesanan untuk setiap pesanan

$H$ : Biaya penyimpanan per unit per tahun

Selanjutnya dilakukan perhitungan frekuensi pemesanan dan interval waktu (IW) pemesanan dengan rumus di bawah ini.

Frekuensi $i_{\text {tools }}=\frac{\text { demand }}{\text { EOQ }}$

$I W_{\text {tools }}=\frac{1}{\text { Frekuensi } \text { tools }} \times 243$ hari kerja

\section{Safety Stock dan Reorder Point (ROP)}

Safety stock adalah persediaan tambahan yang diadakan untuk melindungi atau menjaga kemungkinan terjadinya kekurangan tools (stock out).

Safety stock $=Z \times S D$

$S D=\sqrt{\frac{\sum_{i=1}^{n}(x i-\bar{X})^{\wedge} 2}{n-1}}$

Keterangan:

\section{$Z \quad$ : Standar Deviasi Demand \\ $S D$ : Faktor pengaman}

Reorder Point (ROP) adalah saat atau titik dimana harus diadakan pesanan lagi sedemikian rupa sehingga kedatangan atau penerimaan material yang dipesan itu adalah tepat waktu dimana persediaan di atas safety stock sama dengan nol.

$R O P=(d \times L)+S S$

Keterangan:
d : Standar Deviasi Demand)
L : Standar Deviasi Demand
SS : Safety stock

\section{Klasifikasi ABC}

Klasifikasi $A B C$ digunakan untuk mengklasifikasikan 27 insert tools jalur CYB berdasarkan tiga kelas, yaitu kelas A, kelas B dan kelas $C$. Pengklasifikasian tersebut dilakukan untuk mengetahui insert tools mana yang perlu dilakukan perhatian lebih dalam melakukan pengendalian persediaan. Klasifikasi ABC merupakan klasifikasi dari suatu kelompok material, bahan baku atau aset dalam susunan menurun berdasarkan biaya penggunaan material itu per periode waktu (harga per unit material atau aset dikalikan volume penggunaan dari material itu selama periode waktu tertentu).

Tahapan yang dapat dilakukan yang pertama adalah mendata persediaan yang akan dikelompokkan. Data yang diperlukan diantaranya nama persediaan, berapa banyak demand dalam satu tahunnya, berapa biaya satuan untuk setiap unit persediaan dan jumlah harga untuk setiap persediaan. Untuk jumlah harga keseluruhan persediaan juga diperlukan. Kemudian masukkan seluruh data yang diperlukan. Lalu menghitung persentase untuk setiap komponen persediaan dengan contoh rumus sebagai berikut:

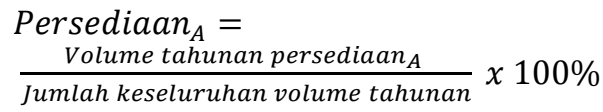

Volume tahunan persediaan adalah demand dikali harga tiap unit. Setelah mendapatkan persentase masing-masing persediaan kemudian mencari persentase kumulatif untuk setiap komponen persediaan. Langkah selanjutnya adalah mengurutkan berdasarkan persentase dari yang paling besar hingga terkecil. Dari urutan inilah dapat dicari komponen mana yang akan masuk ke kelas A, B maupun C.

Pada tahap pembahasan dan analisis penulis menjelaskan hasil dari pengolahan data yang akan menjadi pertimbangan oleh perusahaan untuk kebijakan pengadaan pengendalian persediaan insert tools. Sedangkan penutup berisi dari kesimpulan saran dari penelitian yang telah dilakukan.

\section{HASIL DAN PEMBAHASAN Hasil EOQ}

Insert tools mempunyai 24 kode (Tabel 1) dan berdasarkan pengolahan data menunjukan bahwa hubungan antara EOQ, Safety Stock dan ROP dari insert tools selama semester 2019-2020 dapat dijadikan acuan untuk dijadikan pengendalian persediaan untuk pengadaan di gudang tools PT. XYZ. 
Tabel 1. Data Insert tools di PT. XYZ

\begin{tabular}{|c|c|c|c|c|c|c|}
\hline No & Kode tools & $\begin{array}{l}\text { Price } \\
\text { (Rp) }\end{array}$ & $D$ (unit) & L (bulan) & $\begin{array}{l}\text { Order } \\
\text { cost } \\
(R p) \\
\end{array}$ & $\begin{array}{l}\text { Holding } \\
\text { cost } \\
(R p) \\
\end{array}$ \\
\hline 1 & $\begin{array}{l}\text { SNMN } 433 \text { ACZ } \\
310\end{array}$ & 83.835 & 1.166 & 1 & 8.384 & 11.932 \\
\hline 2 & $\begin{array}{l}\text { TPGN } 090208 \\
\text { (TPGE 732) }\end{array}$ & 57.724 & 160 & 1 & 5.772 & 11.932 \\
\hline 3 & $\begin{array}{l}\text { SPG } 431 \text { ACZ } \\
310\end{array}$ & 139.075 & 154 & 1 & 13.908 & 11.932 \\
\hline 4 & $\begin{array}{l}\text { LNGX160516 } \\
\text { PNFN }\end{array}$ & 383.000 & 128 & 1 & 38.300 & 11.932 \\
\hline 5 & SDCN 42R & 117.608 & 112 & 1 & 11.761 & 11.932 \\
\hline 6 & $\begin{array}{l}\text { WNZ44 } \\
\text { G10T0420 SX6 }\end{array}$ & 480.000 & 108 & 2 & 48.000 & 11.932 \\
\hline 7 & SPG 422 4reg & 138.008 & 96 & 1 & 13.801 & 11.932 \\
\hline 8 & $\begin{array}{l}\text { 2QP- } \\
\text { CCEW09T30 }\end{array}$ & 1.170 .000 & 84 & 3 & 117.000 & 11.932 \\
\hline 9 & $\begin{array}{l}\text { SPHX } \\
1205 Z C E L G P\end{array}$ & 358.000 & 68 & 2 & 35.800 & 11.932 \\
\hline 10 & SNMA 432 & 70.335 & 60 & 1 & 7.034 & 11.932 \\
\hline 11 & SNGN 090316 & 151.000 & 54 & 1 & 15.100 & 11.932 \\
\hline 12 & $\begin{array}{l}\text { TPGN } 110308 \\
\text { (TPG 222) }\end{array}$ & 57.724 & 54 & 1 & 5.772 & 11.932 \\
\hline 13 & $\begin{array}{l}\text { TPGN } 090204 \\
\text { H1 (TPGL } 731 \text { L) }\end{array}$ & 57.724 & 45 & 1 & 5.772 & 11.932 \\
\hline 14 & SNPL 431M & 211.016 & 35 & 1 & 21.102 & 11.932 \\
\hline 15 & $\begin{array}{l}\text { TPMT } 110204 \\
\text { PS }\end{array}$ & 56.320 & 30 & 5 & 5.632 & 11.932 \\
\hline 16 & $\begin{array}{l}\text { SCMT } 09 \\
\text { T308LF }\end{array}$ & 97.000 & 28 & 2 & 9.700 & 11.932 \\
\hline 17 & $\begin{array}{l}\text { ASMT } 11 \text { T308 } \\
\text { PGR }\end{array}$ & 111.360 & 24 & 3 & 11.136 & 11.932 \\
\hline 18 & SPG 432 & 106.482 & 21 & 1 & 10.648 & 11.932 \\
\hline 19 & TPGW 080204 & 130.900 & 18 & 1 & 13.090 & 11.932 \\
\hline 20 & SPG 431 & 221.000 & 15 & 1 & 22.100 & 11.932 \\
\hline 21 & $\begin{array}{l}\text { XTPGW } \\
\text { 110304LT-P }\end{array}$ & 1.150 .000 & 15 & 2 & 115.000 & 11.932 \\
\hline 22 & SPG 422 3reg & 138.008 & 6 & 1 & 13.801 & 11.932 \\
\hline 23 & TEEN 43R & 117.208 & 6 & 1 & 11.721 & 11.932 \\
\hline 24 & $\begin{array}{l}\text { XTPGW } \\
110304 T-1 H-C \\
\text { HB569 }\end{array}$ & 630.000 & 5 & 2 & 63.000 & 11.932 \\
\hline 25 & SNMG 090304 & 57.200 & 4 & 5 & 5.720 & 11.932 \\
\hline 26 & $\begin{array}{l}\text { TPMT } 110208 \\
\text { PS }\end{array}$ & 56.320 & 3 & 5 & 5.632 & 11.932 \\
\hline 27 & $\begin{array}{l}\text { TPMT } 110202 \\
\text { PS }\end{array}$ & 56.320 & 2 & 5 & 5.632 & 11.932 \\
\hline
\end{tabular}

Order cost merupakan $10 \%$ dari harga satuan tools. Biaya penyimpanan (holding cost) adalah biaya yang dikeluarkan untuk menyimpan bahan baku yang telah dipesan sebelumnya. Pekerjaan mengurus tools yang dilakukan oleh kepala gudang tools $\mathrm{PT}$. XYZ yaitu pemeliharaan gudang dan tools berupa merapikan penyimpanan. Dengan menggunakan rumus EOQ maka didapatkan hasil kuantitas order yang optimal, frekuensi dan interval waktu pembelian (Tabel 2).

\section{Holding Cost $=$}

$\frac{\text { Gaji UMK kepala gudang tools }}{\text { hari kerja (bulan) }} \times \%$ mengurusi tools (8)

Holding Cost $=\frac{4.200 .000}{22 \text { hari }} \times 6 \%$

Holding Cost $=11.932$ 
Tabel 2. EOQ, Frekuensi dan Interval Waktu Pembelian Insert tools

\begin{tabular}{rlrrrrrr}
\hline No & \multicolumn{1}{c}{ Kode tools } & $\boldsymbol{D}$ (unit) & $\begin{array}{c}\text { Order cost } \\
\text { (Rp) }\end{array}$ & $\begin{array}{r}\text { Holding cost } \\
\text { (Rp) }\end{array}$ & $\begin{array}{r}\text { EOQ } \\
\text { (unit) }\end{array}$ & $\begin{array}{r}\text { Frekuensi } \\
\text { (unit) }\end{array}$ & $\begin{array}{r}\text { Interval } \\
\text { (Hari) }\end{array}$ \\
\hline 1 & SNMN 433 ACZ 310 & 1.166 & 8.384 & 11.932 & 41 & 29 & 9 \\
2 & TPGN 090208 (TPGE & 160 & 5.772 & 11.932 & 13 & 13 & 19 \\
732) & & & & & & & \\
4 & SPG 431 ACZ 310 & 154 & 13.908 & 11.932 & 19 & 9 & 27 \\
4 & LNGX160516 PNFN & 128 & 38.300 & 11.932 & 29 & 5 & 49 \\
5 & SDCN 42R & 112 & 11.761 & 11.932 & 15 & 8 & 31 \\
6 & WNZ44 G10T0420 SX6 & 108 & 48.000 & 11.932 & 30 & 4 & 61 \\
7 & SPG 422 4reg & 96 & 13.801 & 11.932 & 15 & 7 & 35 \\
8 & 2QP-CCEW09T30 & 84 & 117.000 & 11.932 & 41 & 3 & 81 \\
9 & SPHX 1205ZCELGP & 68 & 35.800 & 11.932 & 21 & 4 & 61 \\
10 & SNMA 432 & 60 & 7.034 & 11.932 & 9 & 7 & 35 \\
11 & SNGN 090316 & 54 & 15.100 & 11.932 & 12 & 5 & 49 \\
12 & TPGN 110308 (TPG 222) & 54 & 5.772 & 11.932 & 8 & 7 & 35 \\
13 & TPGN 090204 H1 (TPGL & 45 & 5.772 & 11.932 & 7 & 7 & 35 \\
14 & 731 L) & & & & & \\
15 & TPML 431M 110204 PS & 35 & 21.102 & 11.932 & 12 & 3 & 81 \\
16 & SCMT 09 T308LF & 30 & 5.632 & 11.932 & 6 & 5 & 49 \\
17 & ASMT 11T308 PGR & 28 & 9.700 & 11.932 & 7 & 4 & 61 \\
18 & SPG 432 & 24 & 11.136 & 11.932 & 7 & 4 & 61 \\
19 & TPGW 080204 & 21 & 10.648 & 11.932 & 7 & 3 & 81 \\
20 & SPG 431 & 18 & 13.090 & 11.932 & 7 & 3 & 81 \\
21 & XTPGW 110304LT-P & 15 & 22.100 & 11.932 & 8 & 2 & 122 \\
22 & SPG 422 3reg & 15 & 115.000 & 11.932 & 18 & 1 & 243 \\
23 & TEEN 43R & 6 & 13.801 & 11.932 & 4 & 2 & 122 \\
24 & XTPGW 110304T-1H-C & 6 & 11.721 & 11.932 & 4 & 2 & 122 \\
25 & HB569 & 5 & 63.000 & 11.932 & 8 & 1 & 243 \\
26 & TPMG 090304 & & & & & \\
27 & TPMT 110208 PS & 3 & 5.720 & 11.932 & 2 & 2 & 122 \\
& & 5.632 & 11.932 & 2 & 2 & 122 \\
& 2 & 5.632 & 11.932 & 2 & 1 & 243 \\
\hline
\end{tabular}

\section{Safety Stock dan Reorder Point (ROP)}

Pada perhitungan safety stock data yang diperlukan antara lain standar deviasi dan faktor pengaman atau $Z$. Karena perusahaan belum menerapkan safety stock maka belum tersedia juga faktor pengaman yang digunakan maka dari itu penulis menggunakan faktor pengaman $90 \%$ jika dilihat pada tabel distribusi normal maka nilai $Z$ diperoleh sebesar 1,28 . Langkah selanjutnya adalah menentukan Reorder Point (ROP) untuk menjamin persediaan dalam batas aman. ROP berhubungan dengan lead time, rata-rata demand dan safety stock.

$R O P=($ lead time $x$ rata - rata demand $)+$ safety stock

Dengan EOQ, perusahaan dapat menemukan berapa banyak kuantitas insert tools yang harus dipesan dengan jumlah yang paling ekonomis. Karena kuantitas pesanan yang dilakukan oleh perusahaan dengan menggunakan metode EOQ dapat meminimalkan total biaya inventory. Selain mendapatkan kuantitas pesanan yang ekonomis, perusahaan juga dapat menghitung safety stock yaitu persediaan yang diadakan untuk mencegah terjadinya kekurangan persediaan. Secara detail hasil perhitungan safety stock, reorder point dan total inventory cost dapat dilihat pada tabel 2 .

$T I C=\frac{D x S}{Q}+\frac{Q x H}{2}$

Keterangan:

TIC : Total Inventory Cost

$I$ : Permintaan

$S$ : Holding cost

$Q \quad$ : Jumlah barang yang dipesan (EOQ) 
Tabel 2. Rekapitulasi Safety Stock, ROP dan Total Inventory Cost Insert Tools

\begin{tabular}{|c|c|c|c|c|c|c|}
\hline No & Kode tools & $\begin{array}{c}\text { Rata-rata } D \\
\text { (unit) }\end{array}$ & $\begin{array}{c}L \\
\text { (bulan) }\end{array}$ & $\begin{array}{l}\text { Safety } \\
\text { Stock }\end{array}$ & $R O P$ & $\begin{array}{c}T I C \\
(R p)\end{array}$ \\
\hline 1 & SNMN 433 ACZ 310 & 97,17 & 1 & 90 & 168 & $483.038,78$ \\
\hline 2 & $\begin{array}{l}\text { TPGN } 090208 \text { (TPGE } \\
732 \text { ) }\end{array}$ & 13,33 & 1 & 8 & 21 & $148.601,74$ \\
\hline 3 & SPG 431 ACZ 310 & 12,83 & 1 & 12 & 23 & $226.076,22$ \\
\hline 4 & LNGX160516 PNFN & 10,67 & 1 & 26 & 32 & $342.059,64$ \\
\hline 5 & SDCN 42R & 9,33 & 1 & 14 & 21 & $177.302,61$ \\
\hline 6 & WNZ44 G10T0420 SX6 & 9 & 2 & 13 & 28 & $351.777,27$ \\
\hline 7 & SPG 422 4reg & 8 & 1 & 46 & 44 & $177.813,76$ \\
\hline 8 & 2QP-CCEW09T30 & 7 & 3 & 11 & 29 & $484.309,59$ \\
\hline 9 & SPHX 1205ZCELGP & 5,67 & 2 & 4 & 15 & $241.207,90$ \\
\hline 10 & SNMA 432 & 5 & 1 & 9 & 12 & $100.583,18$ \\
\hline 11 & SNGN 090316 & 4,5 & 1 & 5 & 9 & $139.540,91$ \\
\hline 12 & $\begin{array}{l}\text { TPGN } 110308 \text { (TPG } \\
\text { 222) }\end{array}$ & 4,5 & 1 & 4 & 9 & $86.690,97$ \\
\hline 13 & $\begin{array}{l}\text { TPGN } 090204 \text { H1 (TPGL } \\
731 \mathrm{~L} \text { ) }\end{array}$ & 3,75 & 1 & 6 & 8 & $78.869,65$ \\
\hline 14 & SNPL 431M & 2,92 & 1 & 5 & 7 & $133.137,24$ \\
\hline 15 & TPMT 110204 PS & 2,5 & 5 & 6 & 17 & $63.955,45$ \\
\hline 16 & SCMT 09 T308LF & 2,33 & 2 & 2 & 7 & $80.561,36$ \\
\hline 17 & ASMT 11 T308 PGR & 2 & 3 & 4 & 9 & $79.941,94$ \\
\hline 18 & SPG 432 & $1, \overline{75}$ & 1 & 3 & 4 & $73.705,96$ \\
\hline 19 & TPGW 080204 & 1,5 & 1 & 3 & 4 & $75.421,36$ \\
\hline 20 & SPG 431 & 1,25 & 1 & 3 & 4 & $89.164,77$ \\
\hline 21 & XTPGW 110304LT-P & 1,25 & 2 & 2 & 4 & $203.219,70$ \\
\hline 22 & SPG 422 3reg & 0,5 & 1 & 3 & 4 & $44.564,84$ \\
\hline 23 & TEEN 43R & 0,5 & 1 & 3 & 4 & $41.444,84$ \\
\hline 24 & $\begin{array}{l}\text { XTPGW 110304T-1H-C } \\
\text { HB569 }\end{array}$ & 0,42 & 2 & 1 & 2 & $87.102,27$ \\
\hline 25 & SNMG 090304 & 0,33 & 5 & 2 & 3 & $23.371,82$ \\
\hline 26 & TPMT 110208 PS & 0,25 & 5 & 1 & 3 & $20.379,82$ \\
\hline 27 & TPMT 110202 PS & 0,17 & 5 & 1 & 2 & $17.563,82$ \\
\hline
\end{tabular}

Sedangkan untuk pengadaan kembali insert tools di gudang dapat menggunakan 2 parameter. Parameter pertama adalah perusahaan dapat mengadakan pengadaan kembali sesuai dengan interval pembelian. Parameter kedua adalah menggunakan ROP yaitu titik dimana persediaan yang harus ada tindakan pembelian/order kembali untuk memenuhi persediaan insert tools agar tidak terjadi stockout. Berikut contoh dengan grafik pengendalian persediaan untuk insert tools 2QP-CCEW09T30 dengan demand 84 unit (Gambar 1).

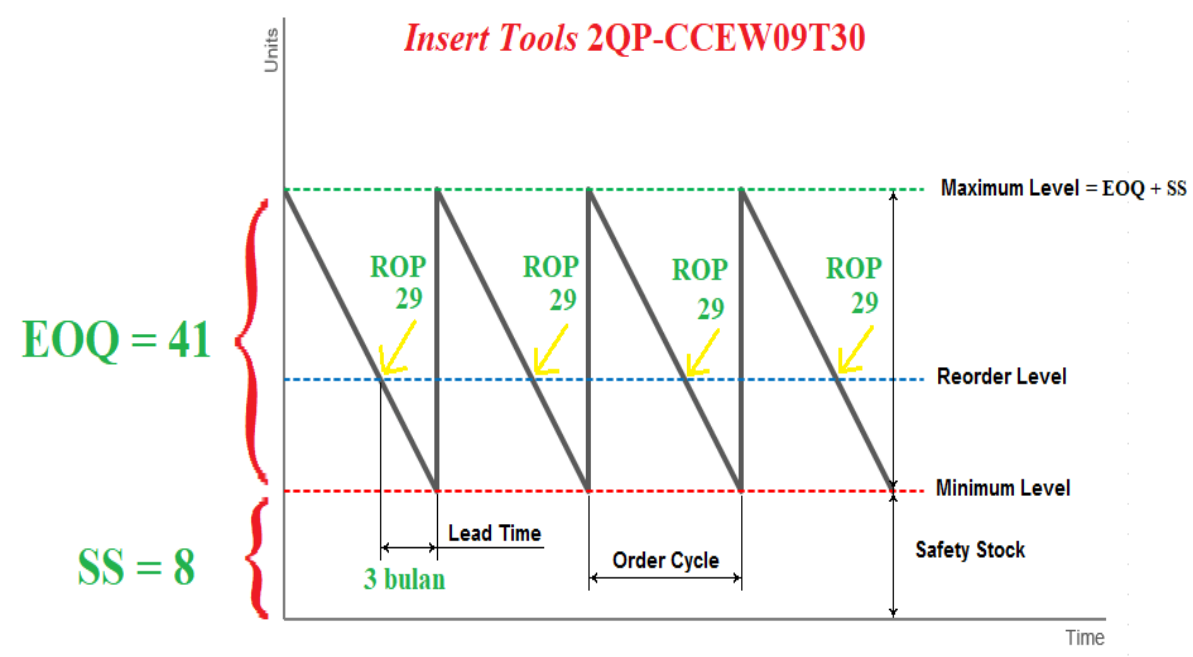

Gambar 1. Pengendalian Persediaan Untuk Insert Tools 2QP-CCEW09T30 
Pada insert tools 2QP-CCEW09T30 dapat dilakukan pengendalian persediaan dengan mengadakan pembelian yang ekonomis menurut $E O Q$ yaitu sebanyak 41 unit untuk pengadaan di gudang, ketika di gudang insert tools 2QPCCEW09T30 sudah menyisakan tinggal 29 unit (ROP) maka harus segera memesan kembali sebanyak 41 unit atau ketika perusahaan tidak menggunakan ROP maka pemesanan kembali dapat menggunakan interval pemesanan yaitu setiap 81 hari sekali. Untuk mencegah kekurangan persediaan insert tools 2QPCCEW09T30 maka perusahaan dapat membuat safety stock sebanyak 8 unit.

\section{Klasifikasi ABC}

Data yang dianalisis adalah data demand insert tools jalur CYB di PT. XYZ semester 20192020 yang dimulai dari bulan April 2019 sampai dengan bulan Maret 2020. Data tersebut kemudian diolah dengan mencari persentase volume tahunan dalam nilai uang. Hal ini dimaksudkan untuk mengetahui berapa persen nilai uang setiap insert tools dibandingkan nilai keseluruhan. Berdasarkan hasil klasifikasi dengan menggunakan software POM for Windows $V$ (Gambar 2) didapatkan 6 insert tools yang masuk kelas A dengan persentase kumulatif $<75 \%$ dari seluruh jumlah insert tools. Kelas $B$ dengan nilai persentasi komulatif $75 \%-90 \%$ dari jumlah seluruh insert tools mempunyai 5 insert tools dan 15 insert tools yang masuk kelas $\mathrm{C}$ dengan persentase kumulatif $90 \%-100 \%$ dari jumlah seluruh insert tools.

Ke 6 insert tools kelas A memiliki nilai uang tahunan yang tinggi, oleh karenanya komponen tersebut masuk ke dalam kelas A. PT. XYZ sebaiknya harus selalu mengecek ketersediaan insert tools tersebut karena sangat berpengaruh pada investasi tahunan perusahaan jika tidak dikendalikan atau diawasi dengan tepat (Ahyadi \& Khodijah, 2017). Pengecekan yang ketat harus selalu dilakukan agar barang selalu tersedia pada waktu yang dibutuhkan. Insert tools pada kelas A harus selalu diprioritaskan dalam pembeliannya dalam jumlah yang optimal.

Volume nilai tahunan pada kelas B cukup besar dan berada di bawah dari nilai tahunan pada kelas A. PT. XYZ sebaiknya selalu mengecek ketersediaan insert tools tersebut. Namun pengecekan tidak seketat pengecekan di kelas $A$ tetapi tetap masih perlu diadakan pengecekan secara berkala agar persediaan selalu tersedia pada saat akan digunakan. Insert tools pada kelas B tidak perlu diprioritaskan dalam pembeliannya namun tetap harus tersedia dalam jumlah minimum. Faktor keamanan persediaan komponen pada kelas ini tetap harus diprioritaskan Jika tidak dijaga dengan baik maka akan timbul kerusakan maupun kerugian yang lainnya yang dapat menimbulkan biaya baru.

\begin{tabular}{|c|c|c|c|c|c|c|}
\hline Item name & Demand & Price & $\begin{array}{l}\text { Dollar } \\
\text { Volume }\end{array}$ & $\begin{array}{l}\text { Percent of } \\
\$ \text {-Vol }\end{array}$ & $\begin{array}{l}\text { Cumultv } \\
\$-\text { vol } \%\end{array}$ & Category \\
\hline 2QP-CCEW09T30 & 84 & 1170000 & 98280000 & 22,27 & 22,27 & A \\
\hline SNMN 433 ACZ 310 & 1166 & 83835 & 97751610 & 22,16 & 44,43 & A \\
\hline WNZ44 G10T0420 SX6 & 108 & 480000 & 51840000 & 11,75 & 56,18 & A \\
\hline LNGX160516 PNFN & 128 & 383000 & 49024000 & 11,11 & 67,29 & A \\
\hline SPHX 1205ZCELGP & 68 & 358000 & 24344000 & 5,52 & 72,81 & A \\
\hline SPG $431 \mathrm{ACZ} 310$ & 154 & 139075 & 21417550 & 4,85 & 77,66 & A \\
\hline XTPGW 110304LT-P & 15 & 1150000 & 17250000 & 3,91 & 81,57 & $\mathrm{~B}$ \\
\hline SPG 422 4reg & 96 & 138008 & 13248770 & 3,0 & 84,57 & B \\
\hline SDCN 42R & 112 & 117608 & 13172100 & 2,99 & 87,56 & B \\
\hline TPGN 090208 (TPGE 732) & 160 & 57724 & 9235840 & 2,09 & 89,65 & B \\
\hline SNGN 090316 & 54 & 151000 & 8154000 & 1,85 & 91,5 & B \\
\hline SNPL 431M & 35 & 211016 & 7385560 & 1,67 & 93,18 & C \\
\hline SNMA 432 & 60 & 70335 & 4220100 &, 96 & 94,13 & $\mathrm{C}$ \\
\hline SPG 431 & 15 & 221000 & 3315000 & .75 & 94,88 & $\mathrm{C}$ \\
\hline XTPGW 110304 T-1H-C HB569 & 5 & 630000 & 3150000 & 71 & 95,6 & $\mathrm{C}$ \\
\hline TPGN 110308 (TPG 222) & 54 & 57724 & 3117096 &, 71 & 96,3 & $\mathrm{C}$ \\
\hline SCMT 09 T308LF & 28 & 97000 & 2716000 & .62 & 96,92 & $\mathrm{C}$ \\
\hline ASMT 11T308 PGR & 24 & 111360 & 2672640 & 61 & 97,52 & $\mathrm{C}$ \\
\hline TPGN 090204 H1 (TPGL 731 L) & 45 & 57724 & 2597580 & .59 & 98,11 & $\mathrm{C}$ \\
\hline TPGW 080204 & 18 & 130900 & 2356200 &, 53 & 98,65 & $\mathrm{C}$ \\
\hline SPG 432 & 21 & 106482 & 2236122 &, 51 & 99,15 & $\mathrm{C}$ \\
\hline TPMT 110204 PS & 30 & 56320 & 1689600 &, 38 & 99,54 & $\mathrm{C}$ \\
\hline SPG 422 3reg & 6 & 138008 & 828048 &, 19 & 99,72 & $\mathrm{C}$ \\
\hline TEEN 43R & 6 & 117208 & 703248 &, 16 & 99,88 & $\mathrm{C}$ \\
\hline SNMG 090304 & 4 & 57200 & 228800 & .05 & 99,94 & $\mathrm{C}$ \\
\hline TPMT 110208 PS & 3 & 56320 & 168960 &, 04 & 99,97 & $\mathrm{C}$ \\
\hline TPMT 110202 PS & 2 & 56320 & 112640 &, 03 & 100 & $\mathrm{C}$ \\
\hline TOTAL & 2501 & & 441215400 & & & \\
\hline
\end{tabular}

Gambar 2. Hasil klasifikasi ABC dengan Software POM Windows 
Jumlah insert tools pada kelas $\mathrm{C}$ ini paling banyak di antara kelas yang lainnya namun volume nilai tahunan pada kelas $C$ ini paling kecil dibandingkan dengan kelas A dan B. Pengendalian persediaan pada kelas $C$ tidak perlu dilakukan pengecekan secara ketat cukup dengan menggunakan metode pemesanan sederhana. Selain itu sebaiknya tetap menyimpan komponen kelas $C$ ini dalam jumlah minimum agar jika akan digunakan selalu tersedia. Untuk faktor keamanan juga tetap harus dilakukan dengan baik, komponen sebaiknya disimpan pada tempat yang terjaga dengan baik agar tidak ada kerusakan maupun kehilangan komponen.

Dengan menerapkan metode klasifikasi $A B C$ pada pengelompokkan persediaan PT. XYZ akan mendapatkan keuntungan, diantaranya memudahkan pemesanan insert toolsl berdasarkan kelas masing-masing. Untuk kelas A harus diprioritaskan untuk pemesanan insert tools karena memiliki nilai volume tahunan yang tinggi yang dapat mempengaruhi investasi perusahaan.

Selain itu, bisa dilakukan penyusunan kembali tata letak komponen yang diletakkan pada gudang. Untuk insert tools yang memiliki demand yang besar dapat ditaruh di bagian depan gudang untuk mempermudah pengambilan barang yang sering digunakan. Penentuan faktor keamanan tiap insert tools juga perlu dilakukan. Untuk insert tools kelas A harus dijaga keamanannya dibanding kelas lain, karena memiliki harga/unit yang tinggi dibanding kelas lain (Wahyuni, 2016).

\section{KESIMPULAN}

Hasil klasifikasi $A B C$ sebagai pengelompokkan atau pengklasifikasian persediaan insert tools yang ada, didapatkan Kelas A terdiri dari 6 jenis, Kelas $B$ terdiri dari 5 jenis dan Kelas $C$ terdiri dari 16 jenis insert tools. Persediaan yang paling berpengaruh pada total nilai persediaan tahunan adalah komponen yang berada pada kelas A karena memiliki volume nilai uang terbesar, sehingga implikasi manajerialnya komponen kelas $A$ harus diprioritaskan. Perhitungan inventory secara berkala terutama untuk kelas A sebaiknya lebih sering dilakukan untuk menjaga tingkat akurasinya. Penelitian selanjutnya dapat dilakukan dengan mempertimbangkan faktor probabilistik dalam permintaannya untuk menentukan kebijakan persediaan yang lebih akurat terutama untuk komponen kelas $\mathrm{A}$.

\section{DAFTAR PUSTAKA}

Ahyadi, H., \& Khodijah, S. (2017). Analisis Pengendalian Persediaan Suku Cadang Pesawat B737-Ng Dengan Pendekatan Model Periodic Review Di PT. X. Bina
Teknika, 13(1), 47-58. Retrieved from https://ejournal.upnvj.ac.id/index.php/BinaT eknika/article/view/1306.

Budiningsih, E., \& Jauhari, W. A. (2017). Analisis Pengendalian Persediaan Spare Part Mesin Produksi di PT. Prima Sejati Sejahtera dengan Metode Continuous Review. PERFORMA : Media IImiah Teknik Industri, 16(2), $\quad$ 152-160. https://doi.org/10.20961/performa.16.2.1699 4.

Farida, I., \& Rozini, M. N. (2016). Pengendalian Persediaan Spare Part dan Pengembangan dengan Konsep 80-20 (Analisis ABC) pada Gudang Suku Cadang PT. Astra International Tbk-Daihatsu Sales Operational Cabang Tegal. In Prosiding Seminar Nasional IPTEK Terapan (SENIT) 2016 Pengembangan Sumber Daya Lokal Berbasis IPTEK (pp. 163-169). Retrieved from

http://ejournal.poltektegal.ac.id/index.php/pr osiding/article/view/374.

Gaspersz, V. (2005). Ekonomi Managerial, edisi revisi: Pembuatan Keputusan Ekonomi. Jakarta:PT. Gramedia Pustaka Utama. Retrieved from Google Scholar.

Graystone, J. (1997). Meeting the colour delivery challenge. Surface Coatings International, $80(11)$, 516-524. https://doi.org/10.1007/BF02692724.

Indriastuty, N., Sukimin, S., Ernayani, R., \& Jayanti, L. I. (2018). Analisis Persediaan Suku Cadang Dengan Metode Economic Order Quantity. Jurnal GeoEkonomi, 9(1), 45-59.

https://doi.org/10.36277/geoekonomi.v9i1.3.

Lukitosari, V. (2012). Penentuan Kuantitas Optimal Dan Reorder Point Pada Persediaan Suku Cadang Dengan Distribusi Gamma. Limits: Journal of Mathematics and Its Applications, 9(1), 33. https://doi.org/10.12962/j1829605X.v9i1.20 89.

Nilawati, A., \& Giyanti, I. (2016). Integrasi Metode $A B C$ dan Multi Item EOQ with Discount dalam Pengendalian Persediaan Obat Dispensing. Tekinfo: Jurnal Ilmiah Teknik Industri Dan Informasi, 4(2), 82-88. Retrieved from http://ejurnal.setiabudi.ac.id/ojs/index.php/te kinfo/article/view/113.

Octaviana, M., Baihaqi, I., \& Bramanti, G. W. (2018). Penetapan Kebijakan Persediaan Spare Parts: Studi Kasus Pabrik Perakitan Sepeda Motor. Jurnal Teknik ITS, 7(1), 4549.

https://doi.org/10.12962/j23373539.v7i1.286 
$\underline{85}$.

Purnomo, H. (2018). Implementasi Kombinasi 3ic Tools Sebagai Penentu Optimasi Pengendalian Persediaan Minyak Goreng. Jurnal Ekonomi, 23(2), 190-202. https://doi.org/10.24912/je.v23i2.368.

Risyahadi, S. T., \& Putri Yunan, H. (2019). Upaya Improvement Pengendalian Persediaan Suku Cadang dengan Metode Fixed Time Period pada PT XYZ. Jurnal Manajemen Industri Dan Logistik, 3(2), 129-140. https://doi.org/10.30988/imil.v3i2.122.

Sato, Y., \& Jauhari, W. A. (2019). Managing critical spare part inventories in an oil drilling company using an economic ordering quantity (EOQ) method. In AIP Conference Proceedings (Vol. 2097, p. 030029). AIP Publishing LLC. https://doi.org/10.1063/1.5098204.

Wahyuni, T. (2016). Penggunaan Analisis ABC untuk Pengendalian Persediaan Barang Habis Pakai: Studi Kasus di Program Vokasi UI. Jurnal Vokasi Indonesia, 3(2). https://doi.org/10.7454/jvi.v3i2.30.

Wibawa, A. P., \& Pujawan, I. N. (2013). Pengendalian Persediaan Barang Jadi Berdasarkan Klasifikasi Produk dan Tingkat Layanan Pelanggan. In Prosiding Seminar Nasional Manajemen Teknologi XVII (pp. 18). Retrieved from http://mmt.its.ac.id/download/SEMNAS/SE MNAS XVII/MI/10. Aditya Putu Wibawa.pdf.

Yamit, Z. (2005). Manajemen persediaan. Yogyakarta: Ekonisia. Retrieved from Google Scholar. 